\title{
A highly sensitive and specific gel-based multiplex RT-PCR assay for the simultaneous and differential diagnosis of African swine fever and Classical swine fever in clinical samples
}

\author{
Montserrat AGÜERO ${ }^{\mathrm{a} *}$, Jovita FERNÁNDEZ ${ }^{\mathrm{b}}$, Luis José ROMERO ${ }^{\mathrm{c}}$, \\ M $^{\mathrm{a}}$ Jesús ZAMORA ${ }^{\mathrm{b}}$, Carmen SÁNCHEZ ${ }^{\mathrm{b}}$, Sandor BELÁK ${ }^{\mathrm{d}}$, Marisa ARIAS ${ }^{\mathrm{b}}$, \\ Jose Manuel SÁNCHEZ-VIZCAÍNO \\ a Laboratorio Central Veterinario, Ministerio de Agricultura, Pesca y Alimentación, \\ Algete, 28110 Madrid, Spain \\ b Centro de Investigación en Sanidad Animal (CISA-INIA), Valdeolmos, 28130 Madrid, Spain \\ c Subdirección General de Sanidad Veterinaria, Ministerio de Agricultura, Pesca y Alimentación, \\ 28028 Madrid, Spain \\ d The National Veterinary Institute \& Faculty of Veterinary and Animal Sciences, \\ The Swedish University of Agricultural Sciences, SE-751 89 Uppsala, Sweden \\ e Dpto. de Sanidad Animal, Facultad de Veterinaria, UCM, avda. Puerta de Hierro s/n, \\ 28040 Madrid, Spain
}

(Received 21 October 2003; accepted 18 March 2004)

\begin{abstract}
The development and standardisation of a novel, highly sensitive and specific one-step hot start multiplex RT-PCR assay is presented for the simultaneous and differential diagnosis of African swine fever (ASF) and Classical swine fever (CSF). The method uses two primer sets, each one specific for the corresponding virus, amplifying DNA fragments different in length, allowing a gel-based differential detection of the PCR products. Universal detection of ASF and CSF virus strains was achieved through selection of primers in conserved viral genome regions. The detection range was confirmed by analysis of a large collection of isolates of the two viruses. The high specificity of the assay was proven by testing related viruses, uninfected cell line cultures and healthy pig tissues. Additional confirmatory tests of the ASF and CSF virus amplicon specificity, based on restriction endonuclease analysis with BsmA I or Ban II, respectively, are also described. The analysis of whole blood and serum samples from experimentally infected animals proved the usefulness of the method for an early diagnosis of both diseases, even before the appearance of the first clinical signs. A study of 150 positive field samples from several ASF and CSF outbreaks showed the suitability of this method for a rapid (less than five hours), sensitive and specific differential diagnosis in clinical samples. In addition, a highly sensitive and specific uniplex RTPCR for CSFV was also developed and standardised as a powerful tool for fast and early diagnosis of the disease.
\end{abstract}

African swine fever virus / Classical swine fever virus / differential diagnosis / multiplex RT-PCR

* Corresponding author: montjose@inicia.es 


\section{INTRODUCTION}

African swine fever (ASF) and Classical swine fever (CSF) are two highly contagious viral diseases of swine affecting domestic pig and wild boar populations. Both diseases are included in OIE List A, because of the high mortality rates associated with the acute forms, that cause huge economic losses in the affected countries, and the potential for extensive and rapid spread at international level.

ASF is caused by African swine fever virus (ASFV), a complex double stranded DNA virus, classified as the only member of genus Asfivirus in the family Asfarviridae [28]. The acute form of ASF is characterized by high fever, extensive haemorrhages, pulmonary oedema and intensive necrosis of lymphoid tissue $[11,24]$. During past decades the disease was present as endemic in most of the sub-Saharan countries of Africa, and a significant increase in the ASF outbreaks has occurred since 1997. In these countries, ASF is maintained by a cycle of infection between wild boars, acting as a reservoir, and soft ticks (the biological vector) with transmission to domestic pigs. Since the first introduction of the disease in Europe (Lisbon, 1957), several outbreaks of ASF have taken place in different European and American countries [2,3]. At present the virus is endemic in Sardinia (Italy), where carrier wild boars and domestic pigs recovered from the ASFV infection have been considered involved in maintaining the disease. No treatment or effective vaccine is available against ASF and the disease control is based on a rapid laboratory diagnosis and the enforcement of strict sanitary measures.

CSF is caused by Classical swine fever virus (CSFV), an enveloped virus with a positive single stranded RNA genome, belonging to the Pestivirus genus of the Flaviviridae family [36]. It is closely antigenic and genetically related to the other members of the Pestivirus genus: Bovine Viral Diarrhoea Virus (BVDV) and Border Disease Virus (BDV), alias ovine pestivirus, that sporadically also infect swine herds. CSF has currently a worldwide distribution, even though some countries have successfully eradicated the virus, it represents a constant threat to pig producing countries. In Europe CSFV is maintained within the wild boar population that may re-introduce the disease by contact with domestic pigs [26]. Illegal swill feeding practices have also been considered to be responsible for some of the recent CSF outbreaks in Europe. CSF acute and subacute forms are characterised by haemorrhages and can be easily confused with those observed in ASFV infections. This fact makes the differential diagnosis essential in the case when haemorrhagic symptoms and fever are observed in a swine population. At present a non-vaccination policy is implemented in the EU. A main reason for this ban is that no differentiation between vaccinated and naturally infected animals can be made, when conventional live virus vaccines are used. Recently, new marker vaccines have been introduced in the market, but the discriminatory test accompanying these marker vaccines need to be improved in terms of sensitivity and specificity. At present, CSF control-eradication strategies in the EU are mainly based on an early laboratory diagnosis and implementation of the specific sanitary measures, including stamping out of large numbers of animals in the affected areas and in the surroundings. The losses can be very high. For example, during the 1997-1998 epidemic in The Netherlands 429 CSF-infected herds were depopulated and approximately 1300 herds were slaughtered pre-emptively. In addition millions of pigs of herds not CSF-infected were killed for welfare reasons [34].

The above listed points clearly indicate that the rapid and robust diagnosis of ASF and CSF is extremely important, in order to prevent the huge losses in the swine populations.

ASF and CSF require early diagnosis as an essential tool in epidemiological surveillance programmes. The standard laboratory 
methods for diagnosis of ASFV and CSFV are mainly based on virus isolation in cell culture, which is tedious and time consuming. The PCR is an alternative rapid detection method of the viruses $[6,10]$. It has at least the same sensitivity than standard cell cultures and offers much higher sensitivity and specificity than other available rapid methods such as ELISA and immunofluorescence based assays [23, 30, 35]. Several uniplex PCR-based methods have been reported for ASFV or CSFV detection. However, according to our knowledge, there is no report on the use of multiplex RT-PCR format to detect ASFV and CSFV viruses in a single reaction.

The purpose of this study was the development of a hot-start multiplex RT-PCR for the simultaneous and very rapid detection of ASFV and CSFV.

\section{MATERIALS AND METHODS}

\subsection{Viruses}

ASFV and CSFV isolates as well as other related viruses used throughout this study are listed in Table I.

\subsection{Cell cultures and virus propagation}

ASFV were propagated in pig leukocytes or alveolar macrophages cultures, and virus isolation and haemadsorption tests were performed as previously described $[21,37]$. Other viruses were grown in PK15 cell line (CSFV isolates and Aujeszky's Disease Virus, ADV); MDBK cell line (BVDV and BDV strains); BHK-21 cell line (Foot-and Mouth Disease Virus, FMDV, and Vesicular Stomatitis Virus, VSV); porcine alveolar macrophages (Porcine Respiratory and reproductive Syndrome virus, PRRSV, European variant strain 5710); and MARC-145 cell line (PRRSV, American variant strain VR2332), following standard protocols. PK15, MDBK, and BHK-21 non-infected cell cultures were also used in the specificity assays.

\subsection{Experimental and field samples}

All the in vivo experiments were performed in the BSL-3 animal facilities at CISA, Valdeolmos. Large-white $\times$ Landrace pigs were inoculated with ASFV or CSFV isolates and clinical samples were obtained as follows.

\subsubsection{ASF V experimental samples}

- Serum and EDTA-blood samples from two one year-old pigs intramuscularly inoculated with $10^{4} \mathrm{HADU}_{50}$ of the low virulent ASFV Spain 75 strain, were collected on days $0,1,2,3,4$ and 7 post-inoculation (PI).

- Tissue samples (spleen, kidney, tonsils, lung, liver and lymph nodes) and EDTAblood were obtained at PI day 5 from one pig, three months of age, intramuscularly inoculated with $10^{7} \mathrm{HADU}_{50}$ of ASFV Lisbon 60 strain. For further studies in poorly preserved samples, pieces of kidney samples were kept at room temperature for 0,14 and 28 days.

\subsubsection{CSFV experimental samples}

- Serum samples from two 1 year-old pigs inoculated with CSFV by intramuscular administration of $10^{6} \mathrm{TCID}_{50}$ of Spain 2/ 2001 isolate were collected on PI days 0,1 , $2,3,4,7$ and 14 . One of the pigs was euthanized on PI day 7. From this animal spleen, tonsils and kidney tissue samples were collected.

- Spleen, tonsils, kidney and lymph nodes tissue samples from one pig experimentally infected with CSFV via intramuscular injection of $5 \times 10^{5}$ TCID $_{50}$ of V1240/97 (Paderborn) isolate, sacrificed at PI day 7.

Porcine blood and tissue samples (spleen, kidney, and tonsils) of a healthy donor pig were employed in the specificity assays.

\subsubsection{Field samples}

A collection of 18 sera, 4 blood and 48 tissue ASFV positive samples, recovered 
Table I. Viruses used in specificity assays.

ASFVa,b

American strains $^{\text {a: }}$ Brazil 78, Haiti 78, Dominican Republic 79;

European strains $^{\text {a,b: }}$ : Spain 70, Spain 75, Spain 94, Italy Ca78/1, Italy Nu 84WB, Italy Nu 90/1, Italy $\mathrm{Nu}$ 95/2, Italy $\mathrm{Nu}$ 98, Lisbon 57, Lisbon 60, Malta 78;

African strains ${ }^{a}$ : Uganda 64, Mozambique 64, Katanga 67, Angola 72, Cape Verde 97, Cape Verde 98, Côte d'Ivoire 99, Nigeria 2001.

CSFV strains ${ }^{\mathrm{a}, \mathrm{c}}$

Subgroups 1.1: Alfort 187, Eystrup; 1.2: Brescia; 2.1: Spain 97, V1240/ 97 Paderborn Germany; 2.2: Parma 98; 2.3: 2699/Osterode 82, Switzerland IV/93, Belgium 1189/1, Alfort/Tubingen, VI3837/38 Germany 99, Spain 1/2001, Spain 2/2001, Spain 1/2002, Visbek/Han 95; disparate viruses (outgrouped): Kanagawa 74, Congenital Tremor.

Bovine viral diarrhoea virus (BVDV) strains $\mathrm{s}^{\mathrm{a}, \mathrm{c}, \mathrm{d}}$

Types I: Sanders, NADL, Oregon; II: 61/138 Low Saxony Germany, and 61/120 Low Saxony Germany.

Border disease virus (BDV) strains , e,f $^{\mathrm{s}}$

X818, Moredun, Frijters, and 137/4.

Foot and Mouth disease virus (FMDV) strains ${ }^{\mathrm{a}}$

Serotypes A: $\mathrm{A}_{22}$ Iraq(IRQ24/64); O: $\mathrm{O}_{1}$-Manisa/Turkey 69; C: $\mathrm{C}_{1}$-Noville Switzerland/65; reference strains of serotypes Sat 1, 2, 3, and Asia1.

Vesicular stomatitis virus (VSV) strains ${ }^{\mathrm{a}}$

Serotypes: Indiana type 1 Colorado 1942, and New Jersey Colombia 1964.

Swine vesicular disease virus (SVDV) ${ }^{\mathrm{a}}$

Clinical samples from experimentally infected pigs with UKG27/72 reference strain.

Porcine respiratory and reproductive syndrome virus (PRRSV) strains ${ }^{\mathrm{a}}$

European 5710, and American VR2332.

Aujeszky disease virus (ADV) ${ }^{\mathrm{a}}$

Phylaxia reference strain.

a ASF International reference laboratory (OIE, European Union), Department of Exotic Diseases, Centro de Investigación en Sanidad Animal (CISA-INIA), Valdeolmos, Spain.

b Istituto Zooprofilacttico della Sardegna, Sardegna, Italy.

${ }^{c}$ CSF virus European reference laboratory, Institute of Virology, Hanover, Germany.

d Veterinary Laboratory Agency, Weybridge, United Kingdom.

e Elizabeth MacArthur Agricultural Institute, Camden, Australia.

${ }^{f}$ ID-Lelystad, The Netherlands.

from sick animals of ASF outbreaks occurred in Spain over the period 1960-1994 and more recently in Cape Verde Islands, Côte d'Ivoire and Nigeria; as well as a collection of fifty sera and thirty tissue CSFV positive samples from infected pigs of the Spanish
1997-1998 and 2001-2002 CSF outbreaks, were used for the assessment of the uniplex and multiplex PCR reactions in clinical samples. Both collections proceed from the Department of Exotic Diseases of CISAINIA (Valdeolmos, Spain); where samples 
Table II. Selected ASFV and CSFV primer sets and main characteristics.

\begin{tabular}{|c|c|c|c|c|c|c|}
\hline Primer & Specificity & $\begin{array}{l}\text { Sequence } \\
\left(5^{\prime}-3^{\prime}\right)\end{array}$ & $\begin{array}{l}\text { Genome posi- } \\
\text { tion }\end{array}$ & $\begin{array}{c}\text { Strains } \\
\text { homology } \\
(\%)\end{array}$ & $\begin{array}{c}\text { BVDV/BDV } \\
\text { homology } \\
(\%)\end{array}$ & $\begin{array}{l}\text { Amplicon } \\
\text { length (bp) }\end{array}$ \\
\hline PPA-1 & $\begin{array}{c}\text { ASFV } \\
\text { (VP73 gene) }\end{array}$ & $\begin{array}{c}\text { AGTTATGG- } \\
\text { GAAACCCGACCC }\end{array}$ & $88600-88619^{a}$ & 100 & - & \\
\hline PPA-2 & $\begin{array}{c}\text { ASFV } \\
\text { (VP73 gene) }\end{array}$ & $\begin{array}{c}\text { CCCTGAATCGGAG- } \\
\text { CATCCT }\end{array}$ & $88363-88381^{\mathrm{a}}$ & 100 & - & 257 \\
\hline PPC-3 & $\begin{array}{l}\text { CSFV } \\
\text { (5'NTR) }\end{array}$ & $\begin{array}{c}\text { GGACTAGCAAACG- } \\
\text { GAGGGACT }\end{array}$ & $112-132^{b}$ & 100 & $66.6-85.7$ & \\
\hline PPC-4 & $\begin{array}{c}\text { CSFV } \\
\text { (5'NTR) }\end{array}$ & $\begin{array}{c}\text { TCGAGGTGG- } \\
\text { GCTTCTGCTCACG }\end{array}$ & $198-219^{b}$ & $86.4-100$ & $27.3-54.5$ & 108 \\
\hline
\end{tabular}

a BA71V (accession number U18466).

b Alfort 187 (accession number X87939).

were confirmed to be ASFV or CSFV positive by OIE described reference methods [37].

\subsection{Primers and restriction endonuclease selection}

ASFV specific primers PPA-1/PPA-2, previously described [1], were employed in the multiplex RT-PCR.

CSFV specific primers were designed considering sequences of the 5'NTR of the genome of 55 different pestivirus strains, available in GenBank or in the database of CSF European reference laboratory of Hanover (Germany), that includes 37 CSFV representing subgroups described by Lowings [20]: 1.1, 1.2, 2.1, 2.2, 2.3 and disparate virus outgrouped $[12,13,15,25,27,31-$ 33 ], fourteen BVDV belonging to types I and II [5, 8, 32] and four BDV isolates [4, 29]. Sequences were aligned, using Clustal W software, and five oligonucleotides were primarily selected from highly conserved sequences among the different CSFV strains but showing high divergence with the other pestiviruses. Three primer pairs defining amplicons different in length to the ASFV specific amplicon, were tested in a preliminary uniplex and multiplex RT-PCR study. CSFV primer set, PPC-3/PPC-4 was finally selected on the basis of the best results in both sensitivity and specificity. The oligonucleotide sequence of the ASFV and CSFV primer sets and their main characteristics are summarized in Table II. Oligonucleotides were purchased from Applied Biosystems (Foster City, USA).

A BsmA I site cutting the PPA-1/PPA-2 ASFV amplicon in two fragments of 173 and 84 bp has been previously described [1]. Sequence analysis of the CSFV genome region delimited by PPC-3/PPC-4 primer pair allowed to locate a Ban II restriction endonuclease site, splitting the amplicon in two fragments of 70 and $38 \mathrm{bp}$, that was conserved in the sequence of all the CSFV analysed isolates. The Ban II and BsmA I restriction endonuclease sites were used for additional specificity confirmation of the amplification products.

\subsection{Extraction methods}

Total nucleic acids (DNA and RNA) were purified from $200 \mu \mathrm{L}$ of sample (cell cultures, serum, blood collected in EDTA, tissue homogenates $10 \%$ in PBS) using High Pure PCR Template Preparation Kit (Roche Diagnostics GmbH, Mannheim, Germany), following manufacturer's protocol. Nucleic acids were finally eluted in $50 \mu \mathrm{L}$ of milliQ water. This extraction method was used for any DNA virus and also for CSFV. 
Total RNA was extracted from $100 \mu \mathrm{L}$ of sample (cell cultures, serum, EDTAblood and tissue homogenate $10 \%$ in PBS) with a commercial reagent (Tripure Isolation Reagent, Roche Diagnostics $\mathrm{GmbH}$, Mannheim, Germany), as recommended by the supplier. RNA was resuspended in $10 \mu \mathrm{L}$ of milliQ water. This extraction method was used for any RNA virus except CSFV.

\subsection{Uniplex and multiplex hot start PCR assays}

\subsubsection{ASFV uniplex PCR}

ASFV uniplex hot start PCR was performed as previously described [1]. Briefly, amplification was carried out in a volume of $25 \mu \mathrm{L}$ containing: $2 \mu \mathrm{L}$ of DNA sample, $1 \times$ PCR Buffer II $(50 \mathrm{mM} \mathrm{KCl}, 10 \mathrm{mM}$ Tris$\mathrm{ClH}$ ), $2 \mathrm{mM} \mathrm{MgCl}_{2}, 0.2 \mathrm{mM}$ dNTPs (Roche Diagnostics GmbH, Mannheim, Germany), $0.2 \mu \mathrm{M}$ of both primers and $0.625 \mathrm{U}$ of Taq Gold polymerase (Applied Biosystems, Foster City, USA). Reaction was incubated $10 \mathrm{~min}$ at $95^{\circ} \mathrm{C}$, followed by 40 cycles at $95^{\circ} \mathrm{C} 15 \mathrm{~s}, 62{ }^{\circ} \mathrm{C} 30 \mathrm{~s}, 72{ }^{\circ} \mathrm{C} 30 \mathrm{~s}$, and then 7 min at $72{ }^{\circ} \mathrm{C}$.

\subsubsection{CSFV uniplex and ASF V/CSFV multiplex RT-PCR}

One step RT-PCR kit (Qiagen GmbH, Hilden, Germany) was used in the CSFV uniplex and ASFV/CSFV multiplex hot start RT-PCR. The reactions were done in a volume of $25 \mu \mathrm{L}$ containing: $2 \mu \mathrm{L}$ of DNA/ RNA sample, $1 \times$ Buffer [Tris-Cl, $\mathrm{KCl}$, $\left.\left(\mathrm{NH}_{4}\right)_{2} \mathrm{SO}_{4}\right], 2.5 \mathrm{mM} \mathrm{MgCl} 2,1 \times \mathrm{Q}$ solution, $0.2 \mathrm{mM}$ dNTPs, $0.3 \mu \mathrm{M}$ each of the primers PPC-3/4, 0.6 $\mu \mathrm{M}$ each of the primers PPA-1/2 (only in the multiplex RTPCR) 5 U RNase Inhibitor (Applied Biosystems, Foster City, USA), $1 \mu \mathrm{L}$ Enzyme Mix (Omniscript and Sensiscript Reverse Transcriptases, HotStartTaq DNA polymerase). Reverse transcription-amplification was accomplished in a one-step with the following incubation program: $30 \mathrm{~min}$ at $55^{\circ} \mathrm{C}$,
15 min at $95{ }^{\circ} \mathrm{C}, 40$ cycles at $94{ }^{\circ} \mathrm{C} 30 \mathrm{~s}$, $64{ }^{\circ} \mathrm{C} 30 \mathrm{~s}, 72{ }^{\circ} \mathrm{C} 30 \mathrm{~s}$, and finally $7 \mathrm{~min}$ at $72{ }^{\circ} \mathrm{C}$.

Amplification products were analysed by electrophoresis on a $2 \%$ (ASFV uniplex PCR) or 3\% (CSFV uniplex RT-PCR and multiplex RT-PCR) agarose gel containing $0.5 \mu \mathrm{g} / \mathrm{mL}$ of ethidium bromide.

\subsection{Restriction enzyme analysis}

Analysis with BsmA I or Ban II restriction endonuclease of the respective ASFV or CSFV amplicon was performed in a $20 \mu \mathrm{L}$ volume reaction, using $10 \mu \mathrm{L}$ of the amplification products and $5 \mathrm{U}$ or $10 \mathrm{U}$ of enzyme, respectively. Reactions were incubated for at least $1 \mathrm{~h} 30 \mathrm{~min}$ at $55{ }^{\circ} \mathrm{C}$ (BsmA I) or at $37{ }^{\circ} \mathrm{C}$ (Ban II). Restriction fragments were analysed by electrophoresis on a $3 \%$ agarose gel.

\section{RESULTS}

Five CSFV specific oligonucleotides combined in three PCR primer sets, were primarily designed for their assessment in a preliminary study of the multiplex RT-PCR test together with PPA-1/PPA-2 ASFV specific primers. From all the candidates, primer pairs demonstrating the best sensitivity and specificity results were finally selected for further optimisation and standardisation of the multiplex ASFV/CSFV RT-PCR. In parallel, different methods for simultaneous DNA and RNA isolation were under evaluation looking for the best single DNA and RNA extraction protocol accompanying the multiplex RT-PCR assay. The extraction method based on nucleic acid binding to glass fiber pre-packed in filter tubes, using High pure PCR template preparation kit, was finally selected. Different amplification assays were also performed to select the type of polymerase enzyme and optimise the reaction conditions in the uniplex and multiplex assays. CSF uniplex 


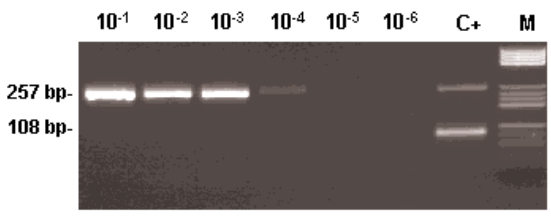

Figure 1. Multiplex RT-PCR sensitivity assay for ASFV detection. DNAs extracted from serial dilutions, in serum, of ASFV Spain70 strain viral suspension with a titre of $1.6 \times 10^{6}$ $\mathrm{HADU}_{50} / \mathrm{mL}$ were employed under reaction conditions described in Methods. C+: Multiplex RT-PCR positive control (CSFV RNA and ASFV DNA); M: molecular weight marker V (Roche Diagnostics GmbH, Mannheim, Germany).

RT-PCR and ASFV/CSFV multiplex RTPCR were finally optimised using the One step RT-PCR kit.

\subsection{Sensitivity assays}

PCR experiments were performed on serial ten-fold dilutions in serum of a viral suspension of ASFV Spain 70 or CSFV Spain $1 / 2001$ with a titre of $1.6 \times 10^{6}$ $\mathrm{HADU}_{50} / \mathrm{mL}$ and $10^{6.6} \mathrm{TCID}_{50} / \mathrm{mL}$, respectively, in order to determine the uniplex and multiplex RT-PCR's lowest detection limit. Purified viral genomes were obtained using High pure PCR template preparation kit. The sensitivity was consistently observed to be $1.2 \mathrm{HADU}_{50}$ for ASFV in the multiplex RT-PCR assay (Fig. 1) and 0.32 TCID $_{50}$, for CSFV by either CSFV uniplex and multiplex RT-PCR (Fig. 2).

\subsection{ASFV and CSFV simultaneous detection by multiplex RT-PCR}

Several ASFV and CSFV virus sample mixtures, containing known amounts of both viruses spiked onto pig serum, were analysed in order to evaluate the efficiency of the extraction method and the novel uniplex or multiplex RT-PCRs in samples containing both viruses. Specific amplified products were found in each sample according to their viral content (Fig. 3). The lowest detection limit of the multiplex RT-PCR assays for CSFV, was the same when only CSFV or both viruses were present in the sample, even though if an imbalance proportion of the two viruses was in it. In the case of ASFV, lowest detection limit in spiked samples containing very big amounts of CSFV was one $\log$ higher than that obtained when ASFV was the only virus in the sample.

\subsection{Specificity of uniplex and multiplex RT-PCR assays}

The specificity of the multiplex RT-PCR and the CSFV uniplex RT-PCR reactions was assessed by analysis of viral genomes from 22 ASFV isolates from European, African and American origins and $17 \mathrm{CSFV}$ strains, representing all the subgroups. All the ASFV strains tested gave a specific positive amplification product of $257 \mathrm{bp}$, in the multiplex RT-PCR assay and showed the expected pattern after Bsm AI restriction endonuclease analysis (data not shown). The

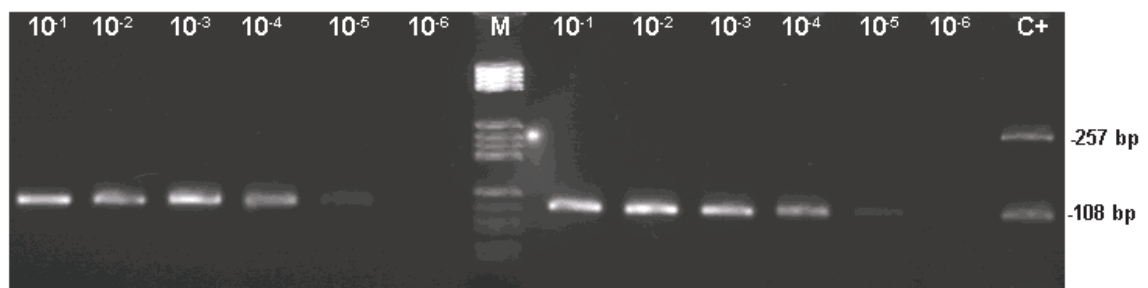

Figure 2. Uniplex (left) and multiplex (right) RT-PCR sensitivity assay for CSFV detection. RNAs extracted from serial dilutions, in serum, of a CSFV Spain 1/2001 strain viral suspension with a titre of $10^{6.6} \mathrm{TCID}_{50} / \mathrm{mL}$ were employed under reaction conditions described in Methods. C+: Multiplex RT-PCR positive control (CSFV RNA and ASFV DNA); M: molecular weight marker V. 


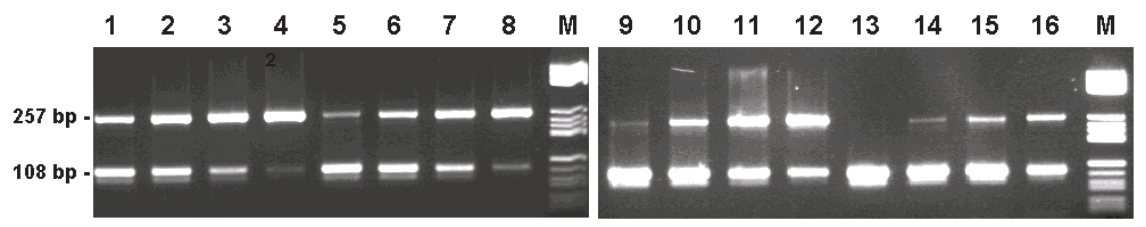

Figure 3. Simultaneous and differential detection of ASFV and CSFV by multiplex RT-PCR in spiked samples containing both viruses in variable proportions. Serum samples containing different dilutions of an ASFV Spain70 strain viral suspension with a titre of $1.6 \times 10^{6} \mathrm{HADU}_{50} / \mathrm{mL}$ and of a CSFV Spain 1/2001 strain viral suspension with a titre of $10^{5.6} \mathrm{TCID}_{50} / \mathrm{mL}$, were analyzed by multiplex RT-PCR. 1: $10^{-1}$ ASFV dilution $+10^{-1}$ CSFV dilution; $2: 10^{-1}$ ASFV dilution $+10^{-2}$ CSFV dilution; $3: 10^{-1}$ ASFV dilution $+10^{-3}$ CSFV dilution; $4: 10^{-1}$ ASFV dilution $+10^{-4}$ CSFV dilution: 5: $10^{-2}$ ASFV dilution $+10^{-1}$ CSFV dilution; $6: 10^{-2}$ ASFV dilution $+10^{-2}$ CSFV dilution; $7: 10^{-2}$ ASFV dilution $+10^{-3}$ CSFV dilution; 8: $10^{-2}$ ASFV dilution $+10^{-4}$ CSFV dilution; 9: $10^{-3}$ ASFV dilution $+10^{-1} \mathrm{CSFV}$ dilution; $10: 10^{-3} \mathrm{ASFV}$ dilution $+10^{-2} \mathrm{CSFV}$ dilution; $11: 10^{-3} \mathrm{ASFV}$ dilution $+10^{-3}$ CSFV dilution; 12: $10^{-3}$ ASFV dilution $+10^{-4}$ CSFV dilution; 13: $10^{-4}$ ASFV dilution $+10^{-1}$ CSFV dilution; $14: 10^{-4}$ ASFV dilution $+10^{-2}$ CSFV dilution; $15: 10^{-4}$ ASFV dilution $+10^{-3}$ CSFV dilution; 16: $10^{-4}$ ASFV dilution $+10^{-4}$ CSFV dilution; M: molecular weight marker V. Reaction conditions are described in Methods.

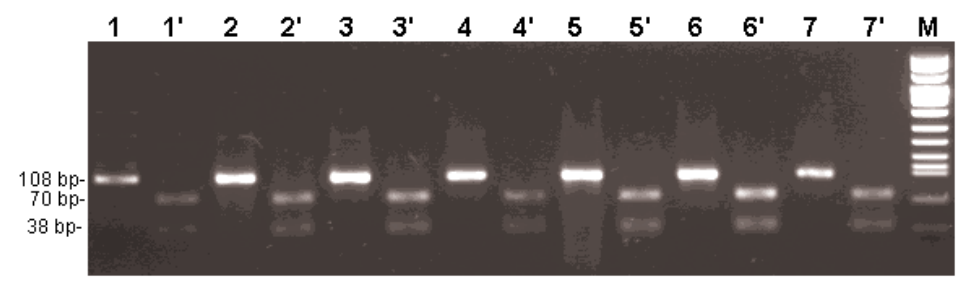

Figure 4. Ban II restriction endonuclease analysis of amplification products of different CSFV strains. 1 and 1': Kanagawa 74 (outgrouped); 2 and 2': Alfort 187 (subgroup 1.1); 3 and 3': Brescia (subgroup 1.2); 4 and 4': Spain 97 (subgroup 2.1); 5 and 5': Parma 98 (subgroup 2.2); 6 and 6': VI3837/38 Germany 99 (subgroup 2.3); 7 and 7': Congenital Tremor (outgrouped). Lanes 1, 2, 3, $4,5,6$, and 7 are amplification products. Lanes 1', 2', 3', 4', 5', 6', and 7' are amplification products after digestion with Ban II. M: molecular weight marker VIII (Roche Diagnostics GmbH, Mannheim, Germany).

$17 \mathrm{CSFV}$ strains analyzed produced an amplicon of $108 \mathrm{bp}$ in both the CSFV uniplex and the multiplex RT-PCR assays. Specificity of the CSFV amplicons was furthermore confirmed by Ban II restriction endonuclease analysis which generated the two expected fragments of 70 and $38 \mathrm{bp}$ in length. Some representative results are shown in Figure 4. Different representative pestiviruses, five BVDV isolates belonging to types I or II, and four BDV isolates, were also evaluated giving no amplification product in all the cases (Fig. 5). Moreover, the viral genomes of other porcine viruses as following: FMDV (the seven serotypes), SVDV, VSV (Indi- ana and New Jersey strains), PRRSV (European and American strains), and ADV, were assayed, giving not amplification signal. Finally, nucleic acids from tissue homogenates, EDTA-blood, and serum samples derived from a healthy pig, and several noninfected cell lines were also tested showing no positive products in any of the uniplex or multiplex PCR assays (data not shown).

\subsection{ASFV and CSFV detection by uniplex or multiplex PCR assays in experimental and field samples}

A viraemia study in blood and/or serum samples was also performed by analysis of 


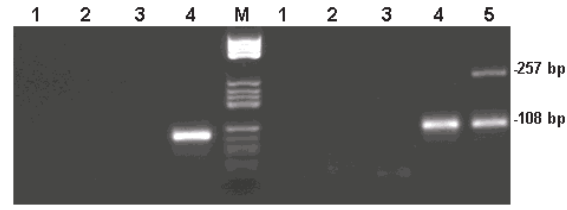

Figure 5. Specificity of individual RT-PCR for CSFV (left) and multiplex ASFV/CSFV RT-PCR (right). 1: BVDV type I strain NADL; 2: BVDV type II strain 61/138 Low Saxony, Germany; 3: BDV strain X818; 4: CSFV strain Spain 1/2001; 5: Multiplex RT-PCR positive control (CSFV RNA and ASFV DNA); M: molecular weight marker V. Purified RNA of the corresponding virus was employed in the individual or multiplex reaction in the conditions described in Methods.

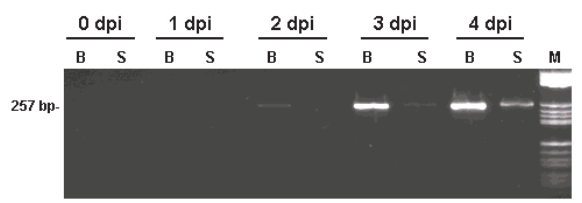

Figure 6. ASFV detection by multiplex RTPCR in EDTA-blood (B) or serum (S) from experimentally infected animals. Samples were obtained at different PI days from pigs inoculated with ASFV Spain 75 strain, as described in Methods. M: molecular weight marker V.

serum and EDTA-blood samples obtained from ASFV or CSFV experimentally infected pigs to determine the time of virus appearance in blood and/or serum. Samples from ASFV-Spain 75 infected pigs at PI days 0 , 1, 2, 3, 4 and 7 and CSFV-Spain 2/2001 infected pigs at $0,1,2,3,4,7$ and 14 PI days were analysed by multiplex RT-PCR and also by the specific uniplex RT-PCR in the case of CSFV samples.

The analysis of EDTA-blood and serum samples from ASFV infected pigs showed positive amplification from PI day 3 in EDTAblood samples and from PI day 4 when serum samples were tested (Fig. 6). Similarly, serum samples recovered from CSFV experimentally infected pigs showed the presence of the virus from PI day 3 both in CSFV uniplex (data not shown) and multiplex RTPCR assays (Fig. 7). Significantly first clin-

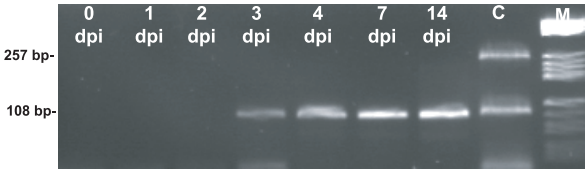

Figure 7. CSFV detection by multiplex RTPCR in serum from experimentally infected animals. Samples were obtained at different dpi from pigs inoculated with CSFV Spain 2/2001 strain, as described in Methods. C: Multiplex RT-PCR positive control (ASFV DNA and CSFV RNA); M: molecular weight marker V.

ical signs (hyperthermia) in the ASFV and CSFV experimentally infected pigs did not appear until PI days 4 and 5, respectively.

To determine the validity of the methods in any clinical sample, tissue samples from experimentally infected pigs with ASFV or CSFV were assayed in uniplex and multiplex RT-PCR. Each one of the tissue samples yielded the corresponding specific ASFV or CSFV amplified product when analysed by both the specific uniplex (data not shown) and multiplex reactions (Fig. 8).

The multiplex RT-PCR analysis of kidney tissue samples from an ASFV infected pig, poorly preserved during 0,14 or 28 days storage at room temperature showed a strong positive amplification signal even after 28 days storage at bad conditions (data not shown).

Finally, PCR studies by uniplex and multiplex assays were performed on a collection of 70 ASFV and 80 CSFV field samples. Presence of virus was detected in all clinical samples by either the respective uniplex PCR or RT-PCR test and by the multiplex RT-PCR (data not shown).

\section{DISCUSSION}

The extensive national and international commercial trade of live animals and products keeps free countries at the constant risk of introduction of exotic diseases. ASF and CSF are two important List A diseases of 


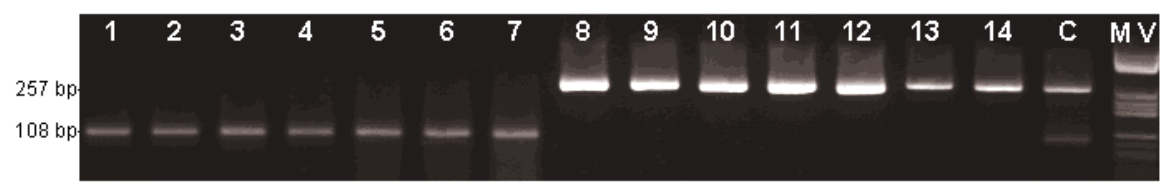

Figure 8. ASFV (right) or CSFV (left) detection by multiplex RT-PCR in different tissue samples from ASFV or CSFV infected pigs. 1-3: Tissue samples from a CSFV Spain 2/2001 strain inoculated pig (1: spleen, 2: tonsil, 3: kidney); 4-7: Tissue samples from a CSFV Paderborn strain infected pig (4: spleen, 5: tonsils, 6: kidney, 7: lymph nodes); 8-14: Tissue samples from an ASFV Lisbon 60 strain inoculated pig (8: EDTA-blood, 9: kidney, 10: liver, 11: lung, 12: lymph nodes, 13: spleen, 14: tonsils); C: Multiplex RT-PCR positive control (ASFV DNA and CSFV RNA); MV: molecular weight marker $\mathrm{V}$.

swine that can be easily confused because of their similar clinical presentation, making mandatory the differential laboratory diagnosis of both viruses in the case of any haemorrhagic fever suspicions. Diagnostic laboratories must have rapid and accurate procedures for use in the surveillance campaigns carried out in free countries. Such methods are also needed in the control and eradication programmes in affected countries, because the rapid detection of infected animals would reduce the potential transmission of the viruses to uninfected herds and would avoid the spread of the disease.

In the last decade, various PCR assays have been developed for the detection of ASFV [1, 18, 35, 37] and of CSFV [16, 17, $19,23,30,38]$. These assays provide novel diagnostic tools, but a disadvantage is the restricted ability to detect only a single virus, ASFV or CSFV. Since ASFV and CSFV cause very similar clinical symptoms, it would be very practical if a single assay could detect and differentiate the two viruses. Such complex method, termed multiplex PCR, is a very useful tool in a diagnostic laboratory.

In this work, a novel highly sensitive and specific multiplex RT-PCR assay is described and applied for the simultaneous and differential detection of ASFV and CSFV. Moreover, a novel highly sensitive and specific uniplex RT-PCR assay for CSFV detection in clinical samples was also standardised and is ready now to use in diagnostic laboratories.

In general, the development of a multiplex PCR assay is not an easy task. The most common problem is that quite a number of primers have to be used in the same reaction tube or well and these molecules may interact with each other, which may block the reaction $[7,9,10,14,22]$. A further problem may be the reliable identification of the various PCR products. To overcome these problems, a very careful primer selection and sequence analysis was performed here, which yielded clear reactions. Specific primer pairs were selected so that amplified DNA fragments could be separated distinctly by size when running agarose-gel electrophoresis. An additional requirement for the CSFV primer-design was that these sequences had to be selected from a highly conserved region in the CSFV genome, in order to provide a general amplification of all possible variants of CSFV. At the same time, the amplification of other pestiviruses (BVDV and BDV) had to be avoided. This requirement was confirmed by testing a panel of BVDV type I and II isolates, as well as a collection of BDV isolates, including those that had demonstrated major cross-reactivity with CSFV.

One of the main keys to set up the singlestep multiplex RT-PCR protocol was the use of an enzyme mix containing hot start DNA polymerase. Since template could be 
DNA (ASFV) or RNA (CSFV) genomes, and a first step of reverse transcription had to be performed at low temperature, the use of a hot start Taq DNA polymerase was essential to avoid non-specific amplifications caused by primer annealing at low temperature. On the other hand, the application of a single tube, single-step procedure makes the present method of ASFV and CSFV simultaneous detection less time consuming and with a decreased risk of cross contamination.

In order to set up a rapid and simple method for the detection of ASF and CSF viral genomes, a simultaneous DNA and RNA purification method from EDTA-blood, serum and tissue samples was also standardised. The purification is very rapid, it requires less than one hour for being accomplished. The use of this method (High pure PCR template preparation kit) in addition to the multiplex RT-PCR assay, allows a rapid approach for the differential detection of the ASFV DNA or CSFV RNA in any clinical sample in a single assay. By running this new assay, the laboratories will obtain a complex diagnosis of ASF and CSF within five hours.

The sensitivity of the multiplex test in comparison to the corresponding uniplex PCR for the detection of each of the two targets, was identical in case of CSFV $(0.32$ $\mathrm{TCID}_{50}$ ) and only one 10 fold decreased in ASFV (0.12 $\mathrm{HADU}_{50}$ in the uniplex assay and 1.2 $\mathrm{HADU}_{50}$ in the multiplex assay). The test also allowed the specific detection of the two viruses simultaneously mixed in spiked samples, resembling a hypothetical co-infection.

Both, uniplex and multiplex tests showed to be highly sensitive for an early detection of ASFV and/or CSFV in clinical samples from infected animals, even though a one day delay in ASF virus detection was observed when using multiplex RT-PCR instead of the specific uniplex PCR assay [1]. ASF and CSF virus detection in EDTA-blood and/or serum was possible from third day postinoculation, even before the first clinical symptoms appearance. It is particularly important in the case of CSF outbreaks because here the specific antibody response does not appear before 14-24 days after infection. In such case the direct virus-detection techniques play the major role for an early and feasible detection of infected animals. In addition, the positive results obtained after multiplex test analysis of bad preserved ASFV tissue samples broaden the range of sample application.

The specificity studies by analysis of 22 different ASFV isolates from different geographical origins, and $17 \mathrm{CSFV}$ isolates representing all the subgroups, clearly demonstrated the uniplex and multiplex methods could be of universal application. The ability to additional checking of the specificity of the amplicons by simple restriction endonuclease digestion, instead of sequencing, also broadens the range of laboratories in which this diagnostic technique can be used with confidence.

In summary, the results of the study showed the use of the hot start one step multiplex RT-PCR and the corresponding uniplex PCRs, in addition to the previous DNA/RNA common extraction method, as a simple, economical and reliable tool for rapid, sensitive and specific differential diagnosis of ASFV or CSFV in clinical samples, even in cases of a hypothetical co-infection.

In the present work the analysis of the amplified targets was carried out by size analysis of DNA fragments on agarose gels. However, detection of a signal specific for a target DNA could be also possible by using fluorescent-labelled hybridisation probes in the near future. In summary, the ASFV/ CSFV multiplex RT-PCR assay proved to be rapid, sensitive and practical. The new method will provide a powerful tool to combat the two major List A viruses of swine.

\section{ACKNOWLEDGEMENTS}

We thank V. Moennig and I. Greiser-Wilke of the Institute of Virology (Hanover, Germany), D. Paton of the Veterinary Laboratories 
Agency (Weybridge, United Kingdom), A.D. Shannon, of the Elizabeth Macarthur Agricultural Institute (Camden, Australia) and A.J. De Smit of the Institute for Animal Science and Health (Lelystad, The Netherlands) for supplying some of the pestivirus isolates. We thank C. Patta of the Istituto Zooprofilacttico (Sardinia, Italy) for supplying the Italian ASFV isolates and M. Moyano, A. Robles, R. Nieto, E. Romero, J.M. Vazquez, and B. Vazquez, for their skillful technical assistance.

This work has been funded by governmental grants (Agreement INIA and Ministry of Agriculture, Spain) and the EU project QLK2-CT2000-00486.

\section{REFERENCES}

[1] Agüero M., Fernández J., Romero L., Sánchez C., Arias M., Sánchez-Vizcaíno J.M., A highly sensitive PCR assay for routine diagnosis of African swine fever virus (ASFV) in clinical samples, J. Clin. Microbiol. 41 (2003) 4431-4434.

[2] Arias M., Sánchez-Vizcaíno J.M., African swine fever (ASF), in: Morilla A., Yoon K.J., Zimmerman J. (Eds.), Trends in emerging viral infections of swine, Iowa State University press, 2002, pp. 119-124.

[3] Arias M., Sánchez-Vizcaíno J.M., African swine fever eradication: the Spanish model, in: Morilla A., Yoon K.J., Zimmerman J. (Eds.), Trends in emerging viral infections of swine, Iowa State University press, 2002, pp. 133-139.

[4] Becher P., Shannon A.D., Tautz N., Thiel H.J., Molecular characterisation of border disease virus, a pestivirus from sheep, Virology 198 (1994) 542-551.

[5] Becher P., Orlich M., Thiel H.J., Mutations in the 5 ' nontranslated region of bovine viral diarrhoea virus result in altered growth characteristics, J. Virol. 74 (2000) 7884-7894.

[6] Belák S., Thorén P., Molecular diagnosis of animal diseases: some experiences over the past decade, Expert Rev. Mol. Diagn. 1 (2001) 434-443.

[7] Burgart L.J., Robinson R.A., Heller M.J., Wilke W.W., Iakoubova O.K., Cheville J.C., Multiplex polymerase chain reaction, Mod. Pathol. 5 (1992) 320-323.

[8] Colett M.S., Larson R., Gold C., Strick D., Anderson D.K., Purchio A.F., Molecular cloning and nucleotide sequence of the pestivirus bovine viral diarrhoea virus, Virology 165 (1988) 191-199.
[9] Edwards M.C., Gibbs R.A., Multiplex PCR: advantages, development, and applications, PCR Methods Appl. 3 (1994) 65-75.

[10] Elnifro E.M., Ashshi A.M., Cooper R.J., Klapper P.E., Multiplex PCR: optimization and application in diagnostic virology, Clin. Microbiol. Rev. 13 (2000) 559-570.

[11] Gomez-Villamandos J., Hervas J., Mendez A., Carrasco L., Villeda C., Wilkinson P., Sierra M., Experimental African swine fever: apoptosis of lymphocytes and virus replication in other cells, J. Gen. Virol. 76 (1995) 2399-2405.

[12] Greiser-Wilke I., Zimmermann B., Fritzemeier J., Floegel G., Moennig V., Structure and presentation of a World Wide Web database of CSF virus isolates held at the EU Reference Laboratory, Vet. Microbiol. 73 (2000) 131136.

[13] Harasawa R., Giangaspero M., Genetic variation in the 5 ' end and NS5B regions of classical swine fever virus genome among Japanese isolates, Microbiol. Immunol. 43 (1999) 373-379.

[14] Henegariu O., Heerema N.A., Dlouhy S.R., Vance G.H., Vogt P.H., Multiplex PCR: critical parameters and step-by-step protocol, Biotechniques 23 (1997) 504-511.

[15] Hofmann M.A., Bossy S., Klassische Schweinepest 1993 in der Schweiz: Molekularepidemiologische Charakterisierung der Virusisolate, Schweiz. Arch. Tierheilkd. 140 (1998) 365-370.

[16] Kaden V., Steyer H., Strebelow G., Lange E., Hubert P., Steinhagen P., Detection of lowvirulent classical swine fever virus in blood of experimentally infected animals: comparison of different methods, Acta Virol. 43 (1999) 373-380.

[17] Katz J.B., Ridpath J.F., Bolin S.R., Presumptive diagnostic differentiation of hog cholera virus from bovine viral diarrhoea and border disease viruses by using a cDNA nestedamplification approach, J. Clin. Microbiol. 31 (1993) 565-568.

[18] King D.P., Reid S.M., Hutchings G.H., Grierson S.S., Wilkinson P.J., Dixon L.K., Bastos D.S., Drew T.W., Development of a TaqMan ${ }^{\circledR}$ PCR assay with internal amplification control for the detection of African swine fever virus, $\mathrm{J}$. Virol. Methods 107 (2003) 53-61.

[19] Lowings J.P., Paton D.J., Sands J.J., De Mia G.M., Rutili D., Classical swine fever: genetic detection and analysis of differences between virus isolates, J. Gen. Virol. 75 (1994) 34613468.

[20] Lowings J.P., Ibata G., Needham J., Paton D.J., Classical swine fever virus diversity and 
evolution, J. Gen. Virol. 77 (1996) 13111321.

[21] Malmquist W.A., Hay D., Hemadsorption and cytophathic effect produced by African swine fever virus in swine bone marrow and buffy coat cultures, Am. J. Vet. Res. 21 (1960) 104108.

[22] Markoulatos P., Siafakas N., Moncany M., Multiplex polymerase chain reaction: a practical approach, J. Clin. Lab. Anal. 16 (2002) 47-51.

[23] McGoldrick A., Lowings J.P., Ibata G., Sands J.J., Belak S., Paton D.J., A novel approach to the detection of classical swine fever virus by RT-PCR with a fluorogenic probe (TaqMan), J. Virol. Methods 72 (1998) 125-135.

[24] Mebus C.A., African swine fever, Adv. Virus Res. 35 (1988) 251-269.

[25] Meyers G., Ruemenapf T., Thiel H.J., Molecular cloning and nucleotide sequence of the genome of hog cholera virus, Virology 171 (1989) 555-567.

[26] Moennig V., Introduction to classical swine fever: virus, disease and control policy, Vet. Microbiol. 73 (2000) 93-102.

[27] Moormann R.J.M., Warmerdam P.A.M., Van der Meer B., Schaper W.M.M., Wensvoort G., Hulst M.M., Molecular cloning and nucleotide sequence of hog cholera virus strain Brescia and location in the genome of the sequence encoding envelope protein E1, Virology 177 (1990) 184-198.

[28] Murphy F.A., Gibbs E.P.J., Horzinek M.A., Studdert M.J., Asfarviridae and Iridoviridae, in: Murphy F.A., Gibbs E.P.J., Horzinek M.A., Studdert M.J. (Eds.), Veterinary Virology (3rd ed.), Academic Press, San Diego, 1999, pp. 293-300.

[29] Ridpath J.F., Bolin S.R., Comparison of the complete genomic sequence of the border disease virus, BD31, to other pestiviruses, Virus Res. 50 (1997) 237-243.
[30] Risatti G.R., Callahan J.D., Nelson W.M., Borca M.V., Rapid detection of classical swine fever virus by a portable real-time reverse transcriptase PCR assay, J. Clin. Microbiol. 41 (2003) 500-505.

[31] Ruggli N., Moser C., Mitchell D., Hofmann M., Tratschin J.D., Baculovirus expression and affinity purification of protein E2 of classical swine fever virus strain Alfort/187, Virus Genes 10 (1995) 115-126.

[32] Sakoda Y., Ozawa S., Damrongwatanapokin S., Sato M., Ishikawa K., Fukusho A., Genetic heterogeneity of porcine and ruminant pestiviruses mainly isolated in Japan, Vet. Microbiol. 65 (1999) 75-86.

[33] Stadejek T., Warg J., Ridpath J.F., Comparative sequence analysis of the 5 ' noncoding region of classical swine fever virus strains from Europe, Asia, and America, Arch. Virol. 141 (1996) 771-777.

[34] Stegeman A., Elbers A., de Smit H., Moser H., Smak J., Pluimers F., The 1997-1998 epidemic of classical swine fever in The Netherlands, Vet. Microbiol. 73 (2000) 183-196.

[35] Steiger Y., Ackermann M., Mettraux C., Kihm U., Rapid and biologically safe diagnosis of African swine fever virus infection by using polymerase chain reaction, J. Clin Microbiol. 30 (1992) 1-8.

[36] Wengler G., Family Flaviviridae, in: Francki R.I.B., Fauquet C.M., Knudson D.L., Brown F. (Eds.), Classification and nomenclature of viruses, Fifth report of the International Committee on Taxonomy of Viruses, Springer, Berlin, 1991, pp. 223-233.

[37] Wilkinson P.J., African swine fever, in: Manual of standards for diagnostic test and vaccines (4th ed.), Office International des Épizooties, Paris, 2000, pp. 189-198.

[38] Wirz B., Tratschin J.D., Muller H.K., Mitchell D.B., Detection of hog cholera virus and differentiation from other pestiviruses by polymerase chain reaction, J. Clin. Microbiol. 31 (1993) 1148-1154. 